\title{
Structure-activity relationships on the odor detectability of homologous carboxylic acids by humans
}

\author{
J. Enrique Cometto-Muñiz $\cdot$ Michael H. Abraham
}

Received: 16 August 2010/Accepted: 18 September 2010/Published online: 8 October 2010

(c) The Author(s) 2010. This article is published with open access at Springerlink.com

\begin{abstract}
We measured concentration detection functions for the odor detectability of the homologs: formic, acetic, butyric, hexanoic, and octanoic acids. Subjects $(14 \leq n \leq 18)$ comprised young (19-37 years), healthy, nonsmoker, and normosmic participants from both genders. Vapors were delivered by air dilution olfactometry, using a three-alternative forced-choice procedure against carbonfiltered air, and an ascending concentration approach. Delivered concentrations were established by gas chromatography (flame ionization detector) in parallel with testing. Group and individual olfactory functions were modeled by a sigmoid (logistic) equation from which two parameters are calculated: $\mathrm{C}$, the odor detection threshold (ODT) and D, the steepness of the function. Thresholds declined with carbon chain length along formic, acetic, and butyric acid where they reached a minimum (ODTs $=514$, 5.2 , and $0.26 \mathrm{ppb}$ by volume, respectively). Then, they increased for hexanoic (1.0 ppb) and octanoic $(0.86 \mathrm{ppb})$ acid. Odor thresholds and interindividual differences in olfactory acuity among these young, normosmic participants were lower than traditionally thought and reported. No significant effects of gender on odor detectability were
\end{abstract}

Electronic supplementary material The online version of this article (doi:10.1007/s00221-010-2430-0) contains supplementary material, which is available to authorized users.

\section{J. E. Cometto-Muñiz (ه)}

Chemosensory Perception Laboratory,

Department of Surgery (Otolaryngology),

University of California, San Diego, 9500 Gilman Dr.,

Mail Code 0957, La Jolla, CA 92093-0957, USA

e-mail: ecometto@ucsd.edu

M. H. Abraham

Department of Chemistry, University College London,

20 Gordon Street, London WC1H OAJ, UK observed. The finding of an optimum molecular size for odor potency along homologs confirms a prediction made by a model of ODTs based on a solvation equation. We discuss the mechanistic implications of this model for the process of olfactory detection.

Keywords Olfactory detectability $\cdot$ Homologous carboxylic acids - Concentration detection odor functions . Olfactory potency $\cdot$ Odor thresholds .

Olfactory structure-activity relationships

\section{Introduction}

Olfactory studies indicate that the detection of odorants by olfactory receptors (ORs) is performed in a combinatorial fashion, such that each receptor can bind different odorants and, conversely, each odorant is capable of binding to various receptors (Malnic et al. 1999). Under such an arrangement, knowledge of how an odorant interacts with one or a few ORs, e.g., Abaffy et al. (2006), Repicky and Luetje (2009), may not predict the olfactory sensitivity of the whole organism to those odorants. Also, structureactivity relationships established at the receptor level via odorant-binding affinity and efficacy to an OR, e.g., Abaffy et al. (2007), might not reflect those seen for olfactory potency at the behavioral level. Comparative data from these two stages of the olfactory system: peripheral receptors and behavior, added to an understanding of processing effects at intermediate stages, e.g., olfactory bulb (Mori et al. 1992; Koulakov et al. 2007; Chen et al. 2009) and cortex (Lei et al. 2006; Rennaker et al. 2007; Stettler and Axel 2009), are necessary to achieve a comprehensive picture of the functional aspects of the sense of smell, among them, odorant sensitivity. 
In the present investigation, we quantified, by measuring concentration detection functions, odor sensitivity in humans to a series of homologous carboxylic acids. These compounds have been the focus of a number of olfactory studies at the behavioral and at the cell/receptor levels. At the behavioral level, this chemical family is an important component in the determination of human body odor (Akutsu et al. 2006; Natsch et al. 2006; Kuhn and Natsch 2009). In fact, malaria vector mosquitoes are attracted and show selective sensitivity with low thresholds, to carboxylic acids present in human sweat (Costantini et al. 2001; Smallegange et al. 2009). In mice, the urinary odor determined by the major histocompatibility complex comprises a mixture of volatile carboxylic acids occurring in relative concentrations that are characteristic of the odor type (unique individual odor) of each animal (Singer et al. 1997). From an environmental perspective, carboxylic acids play an important role in the generation of odor pollution in a variety of environments (Ranau and Steinhart 2005; Wisthaler et al. 2005; van Thriel et al. 2006). From a food-related perspective, some members of the acid series are key aroma compounds in various types of vinegars (Charles et al. 2000; Akakabe et al. 2006; Callejón et al. 2008). From a structure-activity perspective, recent human studies on the odor detection of binary and ternary mixtures of homologous acids often revealed various degrees of additivity among the single components to elicit the detection of the mixture, an effect that was carbon chain length dependent and, in some cases, concentration dependent (Wise et al. 2007; Miyazawa et al. 2008a, $2009 \mathrm{~b}, \mathrm{c})$. There are indications that even subthreshold concentrations of carboxylic acids can enhance the intensity of other odors and flavors (Miyazawa et al. 2008b). At the cell/receptor level, a number of studies have shown that carboxylic acids are strong ligands for a variety of olfactory receptors (Malnic et al. 1999; Saito et al. 2004; Abaffy et al. 2006, 2007; Fujita et al. 2007; Grosmaitre et al. 2009; Repicky and Luetje 2009).

The present study is part of a project that aims to establish structure-activity relationships for human olfactory potency along and across a variety of homologous chemical series and other volatile compounds. Employing a uniform psychophysical and chemico-analytical methodology, the odor potency of each vapor is quantified behaviorally as a complete detectability function, not just as an odor threshold.

\section{Materials and methods}

An institutional review board at the University of California, San Diego, approved the protocol for all experiments described here. All participants provided written informed consent.

\section{Odorants}

The following carboxylic acid homologs were tested (purity and quality within brackets): Formic (95\%, Food Chemical Codex, FCC), acetic ( $\geq 99.5 \%$, FCC), butyric $(\geq 99 \%$, FCC), hexanoic $(98+\%, F C C)$, and octanoic $(98+\%$, FCC) acids. All stimuli were presented in vapor phase and diluted in carbon-filtered air, which also served as blanks.

\section{Subjects}

We recruited a group of 33 subjects (13 males) with an average age $( \pm S D)$ of $23( \pm 4.6)$ years, and ranging from 19 to 37 years old. All participants were nonsmokers and were screened with a clinical olfactory test (Cain 1989) to show normosmia (i.e., a normal sense of smell). Not all subjects were available to be tested with all odorants. Table 1 presents the characteristics of the subgroup tested with each acid.

\section{Apparatus}

The odorant vapors were delivered by an air dilution olfactometer that we have labeled 8-station vapor delivery device (VDD8). A detailed description of the instrument has been recently published (Schmidt and Cain 2010) and
Table 1 Number and characteristics of the subgroups of subjects tested for odor detection of each carboxylic acid and of the common subjects tested with all five acids

\begin{tabular}{llllll}
\hline $\begin{array}{l}\text { Subject } \\
\text { subgroups }\end{array}$ & $\begin{array}{l}\text { Number of } \\
\text { subjects }\end{array}$ & $\begin{array}{l}\text { Average age } \\
\text { (years } \pm \text { SD) }\end{array}$ & $\begin{array}{l}\text { Age } \\
\text { range }\end{array}$ & $\begin{array}{l}\text { Number of } \\
\text { females }\end{array}$ & $\begin{array}{l}\text { Number of } \\
\text { males }\end{array}$ \\
\hline Formic acid & 18 & $24 \pm 5$ & $19-37$ & 12 & 6 \\
Acetic acid & 16 & $22 \pm 3$ & $19-29$ & 10 & 6 \\
Butyric acid & 14 & $24 \pm 5$ & $19-37$ & 9 & 5 \\
Hexanoic acid & 18 & $24 \pm 5$ & $19-37$ & 9 & 9 \\
Octanoic acid & 14 & $23 \pm 3$ & $20-30$ & 8 & 6 \\
Common subjects & 3 & $25 \pm 3$ & $22-27$ & 2 & 1 \\
\hline
\end{tabular}


can also be found in our recent studies of odor detection within other homologous series (Cometto-Muñiz and Abraham 2008, 2009a, b, 2010; Cometto-Muñiz et al. 2008). Key features of the olfactometer include flexibility in the range of delivered concentrations, definable stability of delivery, solvent-free odorant delivery, and a realistic interface with subjects that includes a sufficient supply of odorant stimulus (Schmidt and Cain 2010).

\section{Procedure}

As described in the references just cited, each of the 8 stations of the VDD8 delivers a fixed odorant concentration and comprises three sniffing glass cones. Only one cone presents the odorant (active cone), the other two present carbon-filtered air (blank cones). Delivered concentrations increased by a factor of two from the lowest (in station 8) to the highest (in station 1). Thus, we employed an ascending concentration approach, with a three-alternative forced-choice procedure. At each station, participants decided which cone smelled different and rated their confidence in the decision on a scale ranging from "1" (not confident at all, just guessing) to " 5 " (extremely confident). Up to eight subjects can be tested at a time in succession (when the first subject finishes with station 1, he/ she moves to station 2, and the second subject begins with station 1, and so on). At least one experimenter, and often two, supervised participants throughout testing. A speaker system instructed subjects to sniff from each cone in a 5-s window and to wait $15 \mathrm{~s}$ before continuing to the next station. After all subjects passed through the 8 stations (in what we call a "round"), they leave the room. The experimenter sets a new random order of active cones, waits 5 min (to secure a new steady-state in the VDD8) and calls the subjects again for a new round. All participants completed 35 rounds with the same acid, typically during the course of a day (session). Sessions with a particular acid continued until at least 14 subjects have completed testing. Acids were tested in irregular order.

\section{Analytical chemistry}

During each testing session (day) the concentration of acid in the odor line of the VDD8 (just before achieving the final dilution in the cone) was repeatedly measured via gas chromatography (flame ionization detection, FID). Measurements were taken before the subjects arrived at the laboratory and during the whole testing day (9:30 am$4: 30 \mathrm{pm}$ ) at the rate of $2-4$ samples per hour. Readings from the chromatograph were converted into vapor concentrations (parts per billion by volume, ppb) via a calibration curve for mass, specific for each carboxylic acid, as previously described (Cometto-Muniz et al. 2003). The average coefficient of variation of these concentrations across testing sessions (days) equaled: $38 \%$ for formic, $60 \%$ for acetic, $28 \%$ for butyric, $24 \%$ for hexanoic, and $29 \%$ for octanoic acid. The concentration range tested, in seven binary steps, was $37-4,754 \mathrm{ppb}$ for formic, 0.72-92 $\mathrm{ppb}$ for acetic, $0.037-4.7 \mathrm{ppb}$ for butyric, $0.13-16 \mathrm{ppb}$ for hexanoic, and 0.049-6.3 ppb for octanoic acid.

Data analysis and modeling

Results are presented as plots of detection probability corrected for chance $(P)$ as a function of vapor concentration (log ppb) (called psychometric or detectability functions), and as confidence rating as a function of vapor concentration (log ppb). Correction for chance produced a value between $P=0.0$ (chance detection) and $P=1.0$ (perfect detection) according to (Macmillan and Creelman 1991):

$P=(\mathrm{m} \cdot \mathrm{p}(\mathrm{c})-1) /(\mathrm{m}-1)$

where $P=$ detection probability corrected for chance (i.e., detectability), $\mathrm{m}=$ number of choices per trial (here, three), and $\mathrm{p}(\mathrm{c})=$ proportion correct (i.e., number of correct trials/total number of trials).

Psychometric functions for the group and for individual subjects were modeled using the following sigmoid (logistic) equation:

$P=P_{\max } /\left(1+\mathrm{e}^{(-(\mathrm{x}-\mathrm{C}) / \mathrm{D})}\right)$

where $P=$ detection probability $(0 \leq P \leq 1), P_{\max }=1.0$, $\mathrm{x}=$ vapor concentration ( $\log \mathrm{ppb}$ by volume), and $\mathrm{C}$ and $\mathrm{D}$ are fitted parameters. $\mathrm{C}$ is the value of $\mathrm{x}$ when $P=0.5$, that is, when detection probability is half-way $(P=0.5)$ between chance $(P=0.0)$ and perfect $(P=1.0)$ detection. $\mathrm{C}$ was taken as the odor detection threshold (ODT) expressed in log ppb. In turn, the parameter D defines the steepness of the function such that the smaller the value of $\mathrm{D}$, the steeper the function. Statistical significance of results was established by multivariate analysis of variance (MANOVA) (SuperANOVA v.1.11, Abacus Concepts, Inc., Berkeley, CA).

\section{Results}

Figure 1 (left) shows the group psychometric functions for the five carboxylic acids. From formic to butyric acid, functions increasingly shifted toward lower concentrations with increasing carbon chain length, reflecting increasing odor potency and lower ODTs. The trend was reversed for hexanoic and octanoic acid, whose functions, close to one another, shifted toward higher concentrations and higher 
Table 2 Quantification of the parameters from the group psychometric function for each acid, considering all subjects (upper part) and only the common subjects tested with all five odorants (lower part)

\begin{tabular}{lccccccc}
\hline & $n$ & $\begin{array}{l}\text { ODT } \\
(\mathrm{ppb})\end{array}$ & \multicolumn{1}{l}{$\begin{array}{l}\mathrm{C}(\log \\
\mathrm{ppb})\end{array}$} & $\begin{array}{l}\text { SE } \\
(\mathrm{C})\end{array}$ & $\mathrm{D}$ & \multicolumn{1}{l}{$\mathrm{SE}$} & $R^{2}$ \\
(D) & \\
\hline All subjects & & & & & & & \\
Formic acid & 18 & 514 & 2.711 & 0.062 & 0.30 & 0.06 & 0.954 \\
Acetic acid & 16 & 5.2 & 0.716 & 0.021 & 0.25 & 0.02 & 0.994 \\
Butyric acid & 14 & 0.26 & -0.584 & 0.019 & 0.16 & 0.02 & 0.994 \\
Hexanoic acid & 18 & 1.0 & 0.008 & 0.023 & 0.22 & 0.02 & 0.993 \\
Octanoic acid & 14 & 0.86 & -0.066 & 0.026 & 0.20 & 0.02 & 0.990 \\
Common subjects & & & & & & & \\
Formic acid & 3 & 485 & 2.686 & 0.072 & 0.16 & 0.06 & 0.909 \\
Acetic acid & 3 & 5.7 & 0.759 & 0.045 & 0.18 & 0.04 & 0.970 \\
Butyric acid & 3 & 0.23 & -0.630 & 0.035 & 0.09 & 0.02 & 0.976 \\
Hexanoic acid & 3 & 1.1 & 0.024 & 0.036 & 0.17 & 0.03 & 0.979 \\
Octanoic acid & 3 & 1.1 & 0.042 & 0.038 & 0.20 & 0.03 & 0.981 \\
\hline
\end{tabular}

Columns show number of subjects ( $n$ ), ODT (in ppb), parameters $\mathrm{C}$ ( $\log$ of ODT) and D (function steepness) with their respective standard error (SE), and goodness of fit $\left(R^{2}\right)$

ODTs. The sigmoid Eq. 2 provided a very adequate fit to the group concentration detection data. Table 2 (upper part) quantifies the outcome in terms of ODT (ppb), parameters C (log ODT) and D (steepness of the curve) with their respective standard errors (SE), and the coefficient of determination $\left(R^{2}\right)$. In turn, Fig. 1 (right) illustrates how, as expected, confidence ratings closely followed the trend of the respective detectability data for each acid.

As mentioned, three participants remained available to be tested in common with all five odorants. Figure 2 compares, for each acid, the data from the whole group with that from the common subjects, and Table 2 (lower part) quantifies the results for common subjects. The outcome clearly shows the tight similarity between the two groups in both absolute values and relative trends, lending support to the validity of the comparison across odorants within the study.
We performed a multivariate analysis of variance (MANOVA) to assess the possible role of the factors gender and carboxylic acid (independent variables) on the dependent variables $\mathrm{C}$ (the ODT in log ppb) and D (the odor function steepness). The overall MANOVA showed that only the factor acid was significant $(P=0.0001)$. Post-hoc tests further revealed that only the variable $\mathrm{C}$ was significantly different at the 0.05 level between all pairs of acids except two pairs: hexanoic-octanoic and butyricoctanoic (this pair came very close to significance).

Our strategy included an intensive testing of individual subjects with the aim to make inferences about individual similarities and differences in olfactory detection performance across a group of young and healthy participants from both genders, all nonsmokers, and normosmics. The sigmoid Eq. 2 was then applied to individual psychometric functions for each subject. Supplementary Figures S1 to S5 present these individual concentration detection functions. Each subject was given a univocal number, so subjects tested on more than one odorant can be followed. Table 3 quantifies each individual function in terms of $\mathrm{C}$ (i.e., the individual ODT in $\log \mathrm{ppb}$ ), $\mathrm{D}$, and $R^{2}$. Seventy-one of the 80 individual functions have an $R^{2}$ of 0.9 or higher, illustrating the strong and consistent goodness of fit shown at the single subject level.

\section{Discussion}

Olfactory sensitivity along and across homologous series

The present outcome shows increasing olfactory sensitivity (i.e., decreasing thresholds) with carbon chain length of carboxylic acids up to butyric acid, followed by a decrease in sensitivity (i.e., higher thresholds) for hexanoic and octanoic acids. In a previous study using a less sophisticated delivery system ("squeeze bottles"), we had
Fig. 1 Left Group detectability functions for the odor of the five carboxylic acids. Each symbol represents the outcome of 630 judgments in the cases of formic and hexanoic acids, 560 judgments in the case of acetic acid, and 490 judgments in the cases of butyric and octanoic acids. Right Plots of group average confidence rating as a function of concentration for each acid. In all cases, bars indicate standard error (SE) of the mean
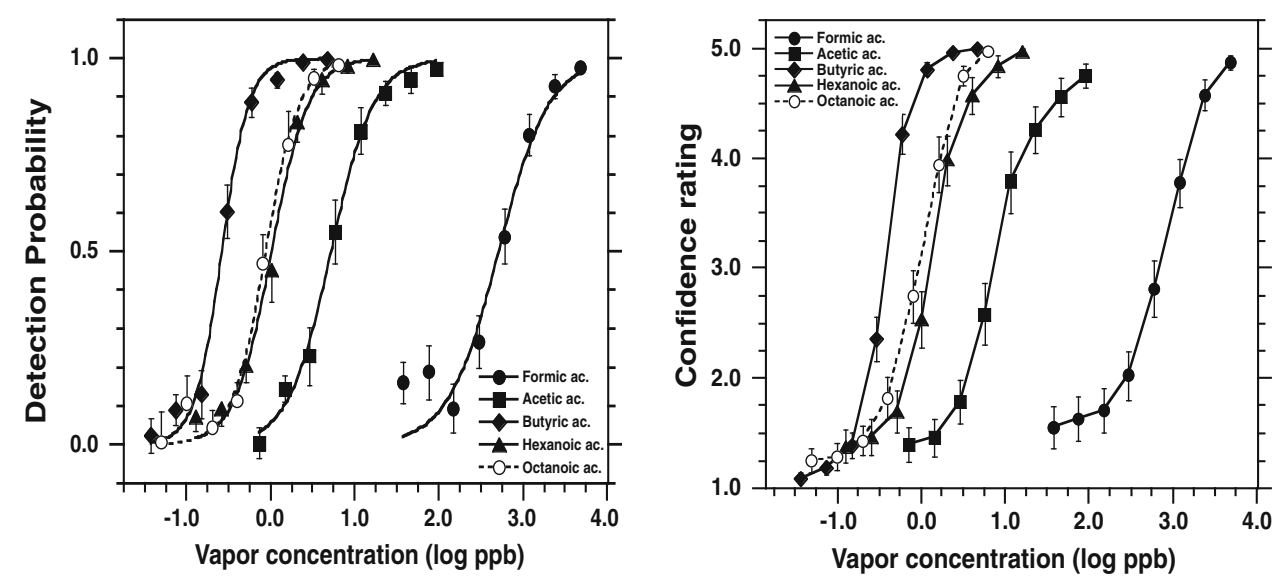
Fig. 2 Showing the close similarity between odor detection functions obtained from all subjects tested with each acid, and those obtained form the common subjects tested with all five acids. Bars represent SE

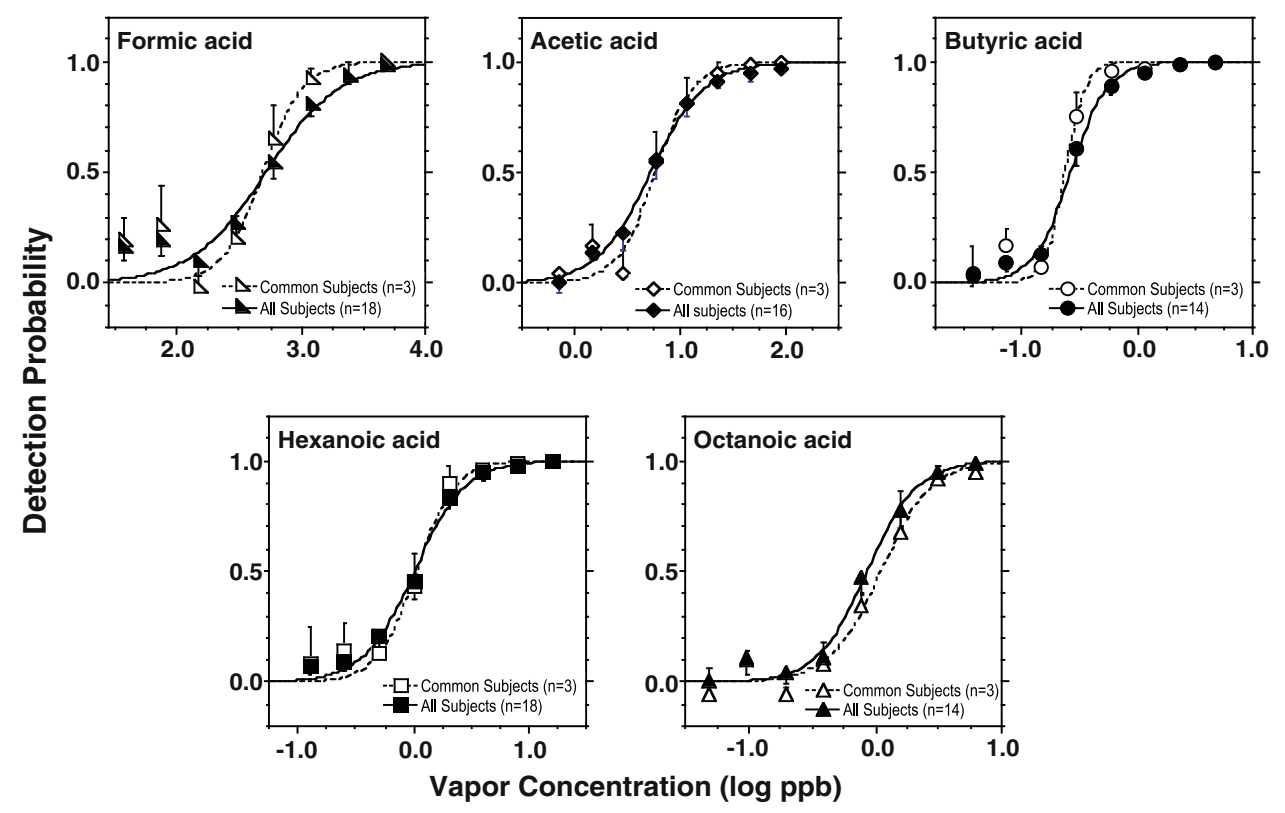

observed the initial trend but failed to capture the final upward threshold rebound seen with the last two homologs, particularly octanoic acid (Cometto-Muniz et al. 1998). In addition, our previous study relied on reported values of vapor pressure to quantify vapors rather than measuring a full calibration curve for mass (Cometto-Muniz et al. 2003) as done here. This difference, added to that on stimulus delivery, likely contributed to the noted discrepancy. The maximum olfactory sensitivity (i.e., lowest threshold) toward the 4-carbon homolog, butyric acid, is not the result of averaging across subjects, since all 14 participants tested with butyric acid were also tested with one or more additional acids, and all showed this outcome (Fig. 3 and Table 3). The ODT pattern across acids found here for humans has similarities with that found for pigtail macaques and, to certain extent, spider monkeys (Laska et al. 2004).

Previous work on odor sensitivity has indicated that the maximum molecular length of an odorant in a homologous series is very important, and it appears that there is an optimum value where odor potency is highest and, thus, ODT is lowest (Abraham et al. 2002). A plot of C (i.e., log ODT) against the maximum length of the carboxylic acid, in Angstroms, clearly shows a minimum around $9 \AA$ (Fig. 4). In addition to molecular length, other factors that could determine high olfactory sensitivity for certain odorants include behavioral relevance and/or frequency of occurrence of the odorant in the chemical environment (Laska et al. 2005). Aside from the acids, human odor studies with homologous acetates (Cometto-Muñiz et al. 2008), alkylbenzenes (Cometto-Muñiz and Abraham 2009a), and aldehydes (Cometto-Muñiz and Abraham 2010) have revealed a minimum in ODT for hexyl acetate, butyl benzene, and octanal, respectively. For n-alcohols (Cometto-Muñiz and Abraham 2008) and 2-ketones (Cometto-Muñiz and Abraham 2009b), the decrease in ODTs with chain length reached a plateau with 1-butanol (continuing to 1-octanol) and 2-heptanone (continuing to 2-nonanone), respectively, and did not significantly rebound. Additional testing with larger homologs (e.g., 1-decanol and 2-undecanone) is needed to confirm or discard the possibility that thresholds might also rebound within alcohols and ketones, as seen for the other three series. Figure 5 illustrates the data discussed above and reveals that the human sense of smell is particularly sensitive to aldehydes and to medium and long chain acids, compared to the other four series.

The olfactory potency of carboxylic acids as ligands for a variety of OR types from human and mouse origin has also been probed via dose-response functions (Grosmaitre et al. 2009; Repicky and Luetje 2009; Saito et al. 2009). In this case, the outcome is measured as "effective concentration 50" $\left(\mathrm{EC}_{50}\right)$, i.e., the concentration producing half $(50 \%)$ the maximum (or reference) response of the particular preparation used (ideally, after all unspecific responses have been discounted). One of these studies probed, under a uniform methodology, an extensive array of 219 mouse and 245 human ORs against 93 odorants including propionic acid and pentanoic to decanoic acids (Saito et al. 2009). Considering the most sensitive ORs tested for each acid, the lowest values of $\mathrm{EC}_{50}$ corresponded to heptanoic acid on mOR31-1, with $\mathrm{EC}_{50}=6.3$ $\mu \mathrm{M}$, and octanoic acid on mOR23-1, with $\mathrm{EC}_{50}=8.3 \mu \mathrm{M}$. Interestingly, another study using a different preparation found that octanoic acid tested also on mOR23-1 produced an $\mathrm{EC}_{50}=10 \pm 6 \mu \mathrm{M}$, very close to the previous value 
Table 3 Quantification of parameters (C, D) and $R^{2}$ for individual psychometric functions

\begin{tabular}{|c|c|c|c|c|c|c|c|c|c|c|c|}
\hline \multicolumn{4}{|c|}{ Formic acid $(n=18)$} & \multicolumn{4}{|c|}{ Acetic acid $(n=16)$} & \multicolumn{4}{|c|}{ Butyric acid $(n=14)$} \\
\hline \multirow{2}{*}{$\frac{\text { Subject }}{1}$} & $\mathrm{C}(\log \mathrm{ppb})$ & \multirow{2}{*}{$\begin{array}{l}\mathrm{D} \\
0.43\end{array}$} & $\mathrm{R}^{2}$ & \multirow{2}{*}{$\frac{\text { Subject }}{4}$} & \multirow{2}{*}{$\begin{array}{l}\mathrm{C}(\log \mathrm{ppb}) \\
1.15\end{array}$} & \multirow{2}{*}{$\begin{array}{l}\mathrm{D} \\
0.23\end{array}$} & \multirow{2}{*}{$\frac{\mathrm{R}^{2}}{0.95}$} & \multirow{2}{*}{$\frac{\text { Subject }}{3}$} & $\mathrm{C}(\log \mathrm{ppb})$ & \multirow{2}{*}{$\begin{array}{l}\mathrm{D} \\
0.12\end{array}$} & \multirow{2}{*}{$\frac{\mathrm{R}^{2}}{0.97}$} \\
\hline & 2.63 & & 0.72 & & & & & & -0.62 & & \\
\hline 2 & 1.65 & 0.44 & 0.92 & 6 & 0.74 & 0.02 & 0.97 & 4 & -0.54 & 0.05 & 0.98 \\
\hline 5 & 3.03 & 0.13 & 0.96 & 8 & 0.84 & 0.31 & 0.99 & 6 & -0.95 & 0.11 & 0.98 \\
\hline 7 & 2.54 & 0.10 & 0.97 & 9 & 0.18 & 0.29 & 0.97 & 8 & -0.52 & 0.19 & 0.97 \\
\hline 10 & 2.62 & 0.33 & 0.93 & 11 & 0.26 & 0.17 & 0.98 & 9 & -0.64 & 0.08 & 0.83 \\
\hline 12 & 2.21 & 0.51 & 0.56 & 12 & 0.56 & 0.21 & 0.91 & 11 & -0.54 & 0.25 & 0.96 \\
\hline 14 & 2.85 & 0.11 & 0.99 & 13 & 0.43 & 0.15 & 0.92 & 12 & -0.69 & 0.07 & 0.89 \\
\hline 15 & 2.79 & 0.15 & 0.98 & 15 & 0.97 & 0.19 & 0.95 & 14 & -0.24 & 0.23 & 0.94 \\
\hline 16 & 2.71 & 0.10 & 0.92 & 16 & 0.76 & 0.10 & 0.98 & 15 & -0.54 & 0.01 & 0.95 \\
\hline 19 & 2.43 & 0.07 & 0.99 & 18 & 0.76 & 0.09 & 0.97 & 16 & -0.59 & 0.13 & 0.98 \\
\hline 20 & 2.95 & 0.13 & 0.93 & 19 & 0.32 & 0.12 & 1.00 & 17 & -0.78 & 0.13 & 1.00 \\
\hline 22 & 2.86 & 0.17 & 0.94 & 20 & 1.58 & 0.32 & 0.80 & 25 & -0.69 & 0.13 & 0.98 \\
\hline 23 & 2.85 & 0.19 & 0.84 & 22 & 0.72 & 0.21 & 0.95 & 28 & -0.33 & 0.09 & 0.96 \\
\hline 25 & 2.78 & 0.15 & 0.93 & 25 & 0.76 & 0.17 & 0.99 & 30 & -0.46 & 0.15 & 0.98 \\
\hline 28 & 2.88 & 0.15 & 0.94 & 27 & 0.90 & 0.21 & 0.97 & & & & \\
\hline 29 & 0.53 & 0.85 & 0.79 & 28 & 0.70 & 0.09 & 0.98 & & & & \\
\hline 31 & 3.08 & 0.21 & 0.96 & & & & & & & & \\
\hline 32 & 3.33 & 0.39 & 0.57 & & & & & & & & \\
\hline Average & 2.60 & 0.26 & & & 0.73 & 0.18 & & & -0.58 & 0.12 & \\
\hline SE & 0.15 & 0.05 & & & 0.09 & 0.02 & & & 0.05 & 0.02 & \\
\hline \multicolumn{6}{|c|}{ Hexanoic acid $(n=18)$} & \multicolumn{6}{|c|}{ Octanoic acid $(n=14)$} \\
\hline Subject & \multicolumn{2}{|c|}{$\mathrm{C}(\log \mathrm{ppb})$} & \multicolumn{2}{|c|}{$\mathrm{D}$} & $R^{2}$ & \multicolumn{2}{|l|}{ Subject } & $\mathrm{C}(\log \mathrm{ppb})$ & $\mathrm{D}$ & & $R^{2}$ \\
\hline 4 & 0.30 & & & 0.01 & 0.99 & 3 & & -0.22 & 0.13 & & 0.98 \\
\hline 6 & -0.53 & & & 0.25 & 0.97 & 4 & & 0.41 & 0.10 & & 0.97 \\
\hline 8 & 0.23 & & & 0.12 & 0.97 & 6 & & -0.18 & 0.05 & & 0.93 \\
\hline 12 & -0.28 & & & 0.35 & 0.82 & 7 & & 0.01 & 0.08 & & 0.97 \\
\hline 14 & -0.16 & & & 0.15 & 1.00 & 8 & & -0.20 & 0.21 & & 0.98 \\
\hline 15 & 0.18 & & & 0.14 & 0.94 & 12 & & 0.03 & 0.18 & & 0.94 \\
\hline 16 & 0.21 & & & 0.05 & 0.91 & 15 & & 0.25 & 0.30 & & 0.90 \\
\hline 17 & 0.09 & & & 0.08 & 0.89 & 18 & & -0.08 & 0.10 & & 0.97 \\
\hline 18 & -0.02 & & & 0.10 & 1.00 & 19 & & -0.10 & 0.02 & & 0.93 \\
\hline 19 & -0.27 & & & 0.02 & 0.89 & 24 & & -0.16 & 0.16 & & 0.92 \\
\hline 21 & -0.40 & & & 0.19 & 1.00 & 25 & & -0.09 & 0.05 & & 0.97 \\
\hline 22 & -0.18 & & & 0.08 & 0.99 & 27 & & -0.12 & 0.01 & & 0.99 \\
\hline 23 & 0.01 & & & 0.11 & 0.93 & 29 & & -2.41 & 1.24 & & 0.24 \\
\hline 25 & 0.04 & & & 0.09 & 0.98 & 30 & & 0.31 & 0.08 & & 0.91 \\
\hline 26 & 0.01 & & & 0.24 & 0.94 & & & & & & \\
\hline 28 & 0.70 & & & 0.20 & 0.89 & & & & & & \\
\hline 31 & 0.26 & & & 0.20 & 0.97 & & & & & & \\
\hline 33 & -0.11 & & & 0.16 & 0.97 & & & & & & \\
\hline Average & 0.005 & & & 0.14 & & & & -0.18 & 0.19 & & \\
\hline SE & 0.07 & & & 0.02 & & & & 0.18 & 0.08 & & \\
\hline
\end{tabular}

(Repicky and Luetje 2009). A different study on the mouse OR SR1 (also known as mOR256-3), expressed in septal organ olfactory sensory neurons (OSNs) and characterized by a broad response profile, reported for octanoic acid an $\mathrm{EC}_{50}=3.2 \mu \mathrm{M}$ (Grosmaitre et al. 2009). These $\mathrm{EC}_{50}$ values represent liquid-phase odorant concentrations, as 


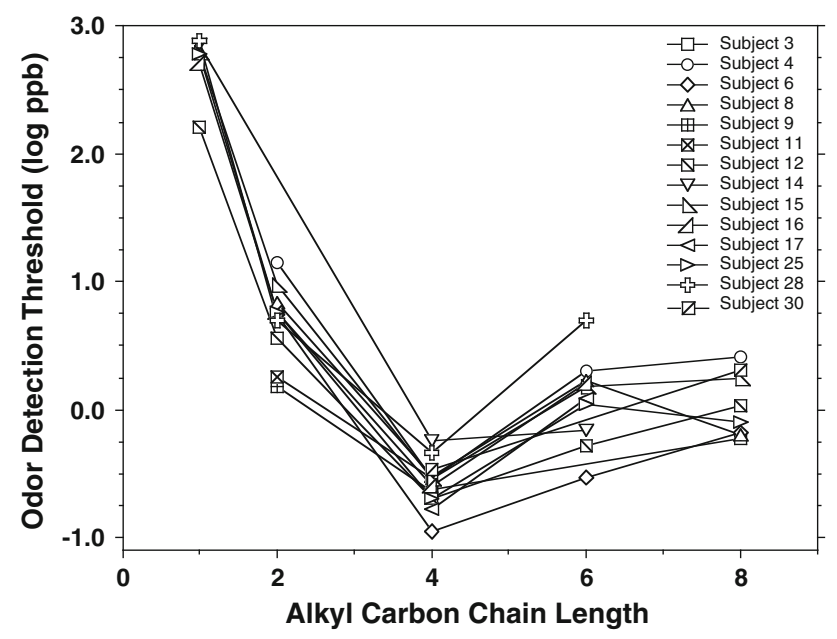

Fig. 3 Individual plots of odor detection thresholds as a function of carbon chain length for the 14 subjects tested with butyric acid, which have also been tested with one or more of the other acids. All participants showed an odor detection threshold minimum for butyric acid

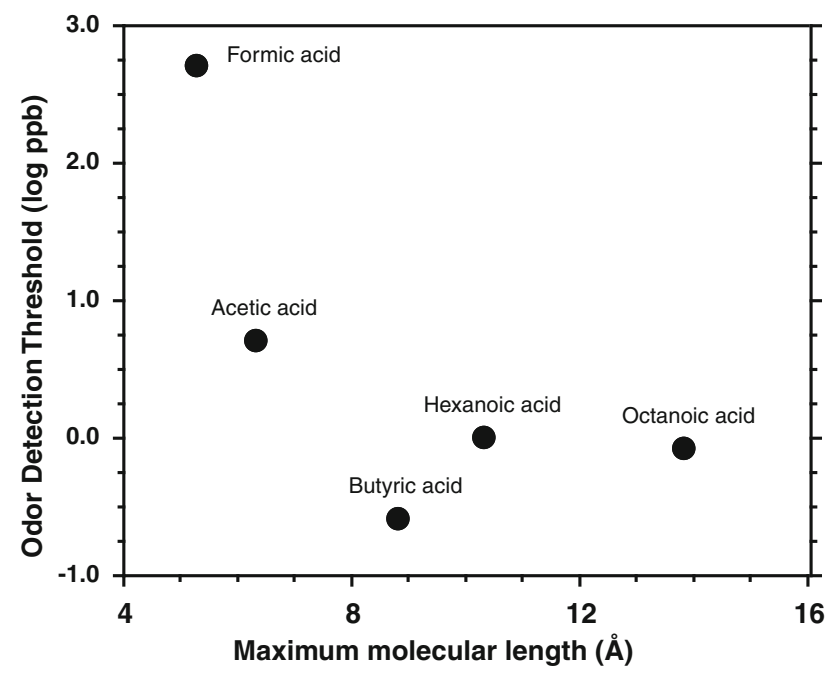

Fig. 4 Plot of C, i.e., odor detection threshold in log ppb by volume, against the maximum molecular length (in Angstroms, $\AA$ ) of carboxylic acids

typically delivered to "in vitro" preparations. When converted into corresponding vapor-phase concentrations (Abraham et al. 2007a; Cometto-Muñiz and Abraham 2010), as delivered in behavioral studies, the same $\mathrm{EC}_{50} \mathrm{~s}$ fall in the $\mathrm{nM}$ range. Although we recognize that $\mathrm{EC}_{50} \mathrm{~S}$ and ODTs, both obtained from concentration detection functions, underlie different concepts and are not directly comparable, we note that ODTs for the acids are still at least 1-2 orders of magnitude lower than vapor-converted $\mathrm{EC}_{50} \mathrm{~s}$. The gap has also been observed for other series (Cometto-Muñiz and Abraham 2008, 2009b, 2010). Only when odorants are able to be tested against the entire range of OR types from one or another species, will we have the

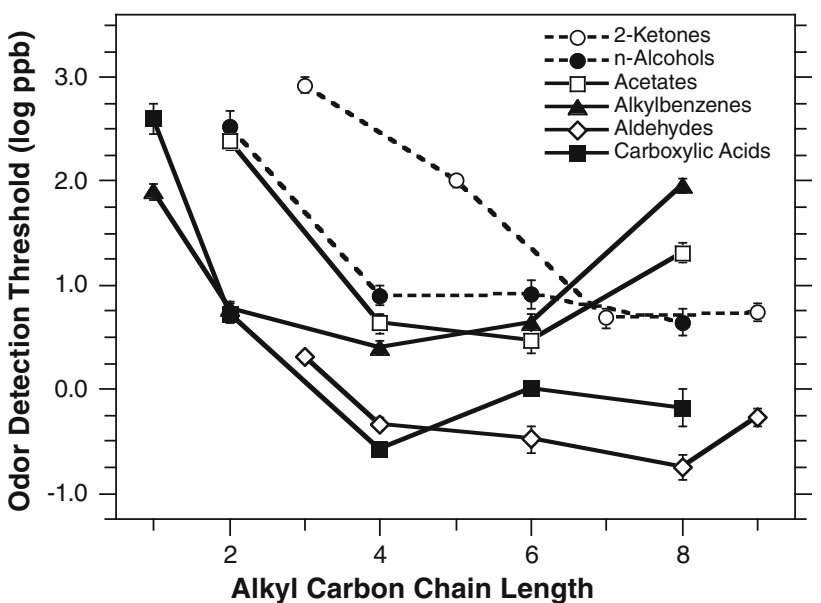

Fig. 5 Trends in odor detection thresholds as a function of the variable carbon chain length for the acids and five other homologous series (Cometto-Muñiz and Abraham 2008, 2009a, b, 2010; ComettoMuñiz et al. 2008; see text). Bars, sometimes hidden by the symbol, indicate SE

means to attempt to project the information obtained from high-throughput screening of ORs into its implications for behavioral chemosensory detection. Until then, measurement and prediction of the overall olfactory potency of airborne chemicals, including structure-activity relationships, needs to rely on a tight psychophysical approach.

As argued and shown recently, e.g. by Cain et al. (2007) and Miyazawa et al. (2009a), the accurate control, quantification, and delivery of chemical vapors produce a significant reduction of "noise" in both the psychophysical and the analytical data. In turn, this translates into ODTs at the very bottom of the extraordinarily wide range of values reported in the literature, e.g., Devos et al. (1990), van Gemert (2003). Is this also true for the ODTs obtained here for the acids? Figure 6 illustrates that, indeed, it is. Furthermore, Fig. 6 (right) compares the present thresholds with those obtained by Nagata (2003) and, more recently, by Wise and colleagues (2007). In particular, the second team of authors also measured ODTs via psychometric functions by using precise air dilution olfactometry and chemico-analytical quantification of vapors (Miyazawa et al. 2009b, c), as done in the present study. The comparison shows very good agreement between the three sources, all of them producing thresholds at the lower end of the range of values from the compilations (Fig. 6). In addition, the ODT minimum at the level of butyric acid within the acid series appears in the three data sources (Fig. 6, right).

Interindividual comparison in olfactory sensitivity

The bulk of the olfactory literature reports that the range in odor detection thresholds for a given odorant across 


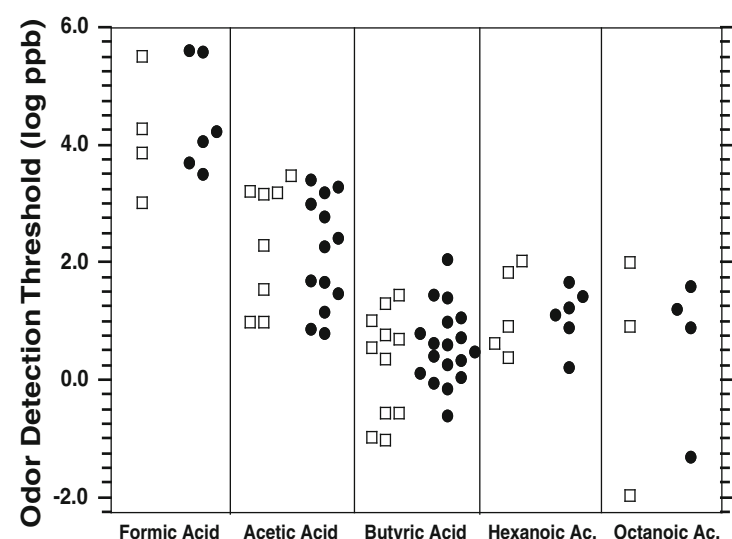

Fig. 6 Left Showing the wide spread of odor detection thresholds reported for each carboxylic acid, as listed in the compilations by van Gemert (2003) (squares) and by Devos et al. (1990) (circles). Right Showing the similarity of odor detection thresholds for each carboxylic acid among three recent sources: the present study

individual subjects amounts to a wide 3-5 orders of magnitude (Jones 1957; Brown et al. 1968; Punter 1983; Yoshida 1984; Stevens et al. 1988). Other investigations have found a much lower range, around 1-2 orders of magnitude (Rabin and Cain 1986; Walker et al. 2003). In recent studies, using the same apparatus and procedure described here, we have measured interindividual sensitivity as the ratio of ODTs between the least and the most sensitive subject among a group of untrained but young, healthy, normosmic, and nonsmoker participants $(16 \leq n \leq 22)$. For the almost two-dozen odorants tested, the ratio ranged between 1 and 2 orders of magnitude (Cometto-Muñiz and Abraham 2008, 2009a, b, 2010; Cometto-Muñiz et al. 2008). For the present acids, the ratio equaled 636 for formic, 25 for acetic, 5.2 for butyric, 17 for hexanoic and 667 for octanoic. With all ratios below three orders of magnitude, they still lean toward the low end of the wide spectrum of intersubject sensitivity generally reported. The larger ratios observed for formic and octanoic acids, compared to our other recent data, were due to just one, and the same, very sensitive subject (S29). Unfortunately, S29 was not available for additional testing. Excluding this consistently most sensitive individual, the ratios reduce to 49 for formic and 4.3 for octanoic acid. To rule out the possibility that some peculiar testing conditions could have played a role in the high sensitivity observed for this participant, we re-checked the data and found that (1) all other subjects tested simultaneously with S29 on each of the two acids did not produce unusually low thresholds (see Table 3 and Supplementary Figures S1 and S5), and (2) measured stimulus concentrations from the sessions where S29 participated agreed with those from other sessions for the respective odorant. These are strong indications that subject S29 had indeed a considerably higher sensitivity

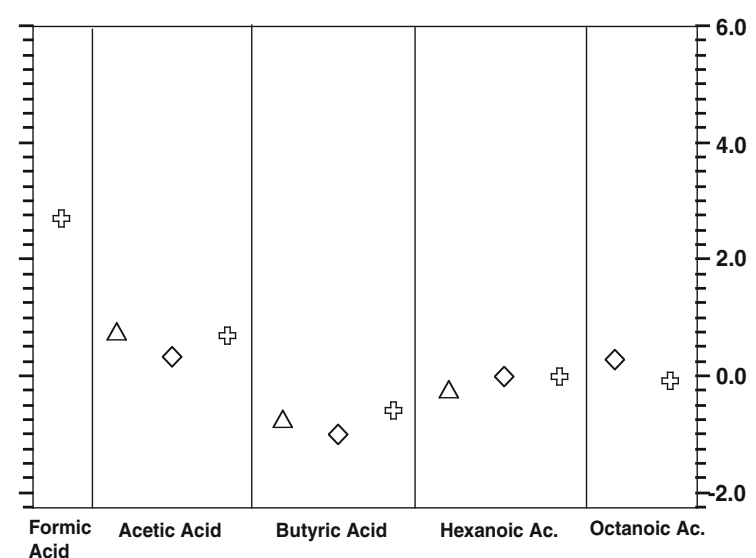

(crosses), Nagata (2003) (triangles), and Wise et al. (2007) (diamonds). Also note that the odor detection thresholds from these three studies appear at the low end of the range of values for each acid listed in the compilations (and shown on the left)

than the other subjects to the two homologs with which this individual was tested. Interestingly, we point out that hyperosmia to another carboxylic acid homolog, isovaleric acid, has been previously described, and shown to have, at least in part, a genetic component (Menashe et al. 2007). Supplementary Figure S6 compares the psychometric functions for the most (including S29) and the least sensitive subject for each acid, and includes their respective confidence ratings at each concentration.

Quantitative structure-activity relationships (QSARs) for the odor detection of volatile organic compounds (VOCs)

Use of carbon chain length within homologous series and of chemical functional group across such series has proven to be useful tools to gain a broad understanding of the general processes that govern the olfactory detection of vapors (Hau and Connell 1998; Abraham et al. 2002). Studies showed that "selective" processes account for some $77 \%$ of the observed odor thresholds, whereas the remainder is due to "specific" processes (Abraham et al. 2002, 2007b, 2010). In contrast, for trigeminal chemesthetic detection, i.e., chemosensory irritation, selective processes account for up to $95 \%$ of observed irritation thresholds (Abraham et al. 1998, 2003). Selective processes rest mainly on the simple transfer of the odorant from the air (gas phase) to the receptor phase (condensed biophase), such that small changes in odorant structure evoke small and predictable changes in odor potency. Specific processes rest mainly on particular odorant/ (olfactory) receptor(s) interactions, such that small changes in odorant structure can have large (and, often, difficult to predict) changes in odor potency. The QSAR model 
applied in these studies is based on a general solvation equation (Abraham et al. 2001), and one of its critical features is to provide a mechanistic interpretation of the olfactory detection of VOCs (Abraham et al. 2007b), as explained next. The model will closely predict the olfactory potency (i.e., ODT) of odorants acting principally by selective effects. In contrast, odorants acting principally by specific effects will show up as outliers to the model, typically in the direction of being more potent than expected (i.e., having lower ODTs than predicted). Even the outliers can provide useful information since they help to identify and define the possible chemical bases for their particular olfactory specificity, responsible for their higher-thanexpected odor potency (Abraham et al. 2007b). Furthermore, the solvation model had predicted that, across homologous series, in addition to the important role played by transfer of the odorant, there should be a significant role for molecular size (in particular, length), such that, beyond a certain maximum size, odor potency will start to decrease (Abraham et al. 2002). The present results support such prediction.

In recent studies, we have collected odor detectability data for a range of VOCs, emphasizing the following: (1) Usage of a uniform and effective psychophysical methodology to facilitate across-study comparisons. (2) Precise generation, efficient delivery, and accurate chemico-analytical quantification of odorants. (3) Measurement of psychometric functions, not just thresholds, and applying a model (sigmoid logistic regression) that provides a tight fit to the experimental results. (4) Gathering intensive group $(14 \leq n \leq 22)$ as well as individual subject olfactory functions. Ultimately, we plan to revisit the above-discussed QSAR model for odor detection potency (Abraham et al. 2002) but using the improved database just described. To do so, we first need to expand testing to an ample number and variety of odorants.

Acknowledgments This work was funded by grant number R01 DC 002741 from the National Institute on Deafness and Other Communication Disorders (NIDCD), National Institutes of Health (NIH). Thanks are due to E. Moreno-Davis for excellent technical assistance and to D. Tran, N. Astaraei, and A. Tzigantcheva for their help in testing subjects, and gathering, processing and plotting data.

Open Access This article is distributed under the terms of the Creative Commons Attribution Noncommercial License which permits any noncommercial use, distribution, and reproduction in any medium, provided the original author(s) and source are credited.

\section{References}

Abaffy T, Matsunami H, Luetje CW (2006) Functional analysis of a mammalian odorant receptor subfamily. J Neurochem 97:1506-1518
Abaffy T, Malhotra A, Luetje CW (2007) The molecular basis for ligand specificity in a mouse olfactory receptor: a network of functionally important residues. J Biol Chem 282:1216-1224

Abraham MH, Kumarsingh R, Cometto-Muniz JE, Cain WS (1998) An algorithm for nasal pungency thresholds in man. Arch Toxicol 72:227-232

Abraham MH, Gola JMR, Cometto-Muñiz JE, Cain WS (2001) The correlation and prediction of VOC thresholds for nasal pungency, eye irritation and odour in humans. Indoor Built Environ 10:252-257

Abraham MH, Gola JM, Cometto-Muniz JE, Cain WS (2002) A model for odour thresholds. Chem Senses 27:95-104

Abraham MH, Hassanisadi M, Jalali-Heravi M, Ghafourian T, Cain WS, Cometto-Muniz JE (2003) Draize rabbit eye test compatibility with eye irritation thresholds in humans: a quantitative structure-activity relationship analysis. Toxicol Sci 76:384-391

Abraham MH, Ibrahim A, Acree WE (2007a) Partition of compounds from gas to water and from gas to physiological saline at $310 \mathrm{~K}$ : linear free energy relationships. Fluid Phase Equilib 251:93-109

Abraham MH, Sanchez-Moreno R, Cometto-Muniz JE, Cain WS (2007b) A quantitative structure activity analysis on the relative sensitivity of the olfactory and the nasal trigeminal chemosensory systems. Chem Senses 32:711-719

Abraham MH, Sanchez-Moreno R, Gil-Lostes J, Acree WE Jr, Cometto-Muniz JE, Cain WS (2010) The biological and toxicological activity of gases and vapors. Toxicol In Vitro 24:357-362

Akakabe Y, Tamura Y, Iwamoto S, Takabayashi M, Nyuugaku T (2006) Volatile organic compounds with characteristic odor in bamboo vinegar. Biosci Biotechnol Biochem 70:2797-2799

Akutsu T, Sekiguchi K, Ohmori T, Sakurada K (2006) Individual comparisons of the levels of (E)-3-methyl-2-hexenoic acid, an axillary odor-related compound, in Japanese. Chem Senses 31:557-563

Brown KS, Maclean CM, Robinette RR (1968) The distribution of the sensitivity to chemical odors in man. Hum Biol 40:456-472

Cain WS (1989) Testing olfaction in a clinical setting. Ear Nose Throat J 68:316-328

Cain WS, Schmidt R, Wolkoff P (2007) Olfactory detection of ozone and D-limonene: reactants in indoor spaces. Indoor Air 17:337-347

Callejón RM, Morales ML, Troncoso AM, Silva Ferreira AC (2008) Targeting key aromatic substances on the typical aroma of sherry vinegar. J Agric Food Chem 56:6631-6639

Charles M, Martin B, Ginies C, Etievant P, Coste G, Guichard E (2000) Potent aroma compounds of two red wine vinegars. J Agric Food Chem 48:70-77

Chen TW, Lin BJ, Schild D (2009) Odor coding by modules of coherent mitral/tufted cells in the vertebrate olfactory bulb. Proc Natl Acad Sci USA 106:2401-2406

Cometto-Muñiz JE, Abraham MH (2008) Human olfactory detection of homologous n-alcohols measured via concentration-response functions. Pharmacol Biochem Behav 89:279-291

Cometto-Muñiz JE, Abraham MH (2009a) Olfactory detectability of homologous n-alkylbenzenes as reflected by concentrationdetection functions in humans. Neuroscience 161:236-248

Cometto-Muñiz JE, Abraham MH (2009b) Olfactory psychometric functions for homologous 2-ketones. Behav Brain Res 201:207-215

Cometto-Muñiz JE, Abraham MH (2010) Odor detection by humans of lineal aliphatic aldehydes and helional as gauged by doseresponse functions. Chem Senses 35:289-299

Cometto-Muniz JE, Cain WS, Abraham MH (1998) Nasal pungency and odor of homologous aldehydes and carboxylic acids. Exp Brain Res 118:180-188 
Cometto-Muniz JE, Cain WS, Abraham MH (2003) Quantification of chemical vapors in chemosensory research. Chem Senses 28:467-477

Cometto-Muñiz JE, Cain WS, Abraham MH, Gil-Lostes J (2008) Concentration-detection functions for the odor of homologous nacetate esters. Physiol Behav 95:658-667

Costantini C, Birkett MA, Gibson G, Ziesmann J, Sagnon NF, Mohammed HA, Coluzzi M, Pickett JA (2001) Electroantennogram and behavioural responses of the malaria vector Anopheles gambiae to human-specific sweat components. Med Vet Entomol 15:259-266

Devos M, Patte F, Rouault J, Laffort P, van Gemert LJ (1990) Standardized human olfactory thresholds. IRL Press, Oxford

Fujita Y, Takahashi T, Suzuki A, Kawashima K, Nara F, Koishi R (2007) Deorphanization of Dresden G protein-coupled receptor for an odorant receptor. J Recept Signal Transduct Res 27:323-334

Grosmaitre X, Fuss SH, Lee AC, Adipietro KA, Matsunami H, Mombaerts P, Ma M (2009) SR1, a mouse odorant receptor with an unusually broad response profile. J Neurosci 29:14545-14552

Hau KM, Connell DW (1998) Quantitative structure-activity relationships (QSARs) for odor thresholds of volatile organic compounds (VOCs). Indoor Air 8:23-33

Jones FN (1957) An analysis of individual differences in olfactory thresholds. Am J Psychol 70:227-232

Koulakov A, Gelperin A, Rinberg D (2007) Olfactory coding with allor-nothing glomeruli. J Neurophysiol 98:3134-3142

Kuhn F, Natsch A (2009) Body odour of monozygotic human twins: a common pattern of odorant carboxylic acids released by a bacterial aminoacylase from axilla secretions contributing to an inherited body odour type. J R Soc Interface 6:377-392

Laska M, Wieser A, Rivas Bautista RM, Hernandez Salazar LT (2004) Olfactory sensitivity for carboxylic acids in spider monkeys and pigtail macaques. Chem Senses 29:101-109

Laska M, Fendt M, Wieser A, Endres T, Hernandez Salazar LT, Apfelbach R (2005) Detecting danger-or just another odorant? Olfactory sensitivity for the fox odor component 2,4,5-trimethylthiazoline in four species of mammals. Physiol Behav 84:211-215

Lei H, Mooney R, Katz LC (2006) Synaptic integration of olfactory information in mouse anterior olfactory nucleus. J Neurosci 26:12023-12032

Macmillan NA, Creelman CD (1991) Detection theory: a user's guide. Cambridge University Press, Cambridge

Malnic B, Hirono J, Sato T, Buck LB (1999) Combinatorial receptor codes for odors. Cell 96:713-723

Menashe I, Abaffy T, Hasin Y, Goshen S, Yahalom V, Luetje CW, Lancet D (2007) Genetic elucidation of human hyperosmia to isovaleric acid. PLoS Biol 5:e284

Miyazawa T, Gallagher M, Preti G, Wise PM (2008a) Synergistic mixture interactions in detection of perithreshold odors by humans. Chem Senses 33:363-369

Miyazawa T, Gallagher M, Preti G, Wise PM (2008b) The impact of subthreshold carboxylic acids on the odor intensity of suprathreshold flavor compounds. Chemosens Percept 1:163-167

Miyazawa T, Gallagher M, Preti G, Wise PM (2009a) Methodological factors in odor detection by humans. Chemosens Percept 2:195-202

Miyazawa T, Gallagher M, Preti G, Wise PM (2009b) Odor detection of mixtures of homologous carboxylic acids and coffee aroma compounds by humans. J Agric Food Chem 57:9895-9901

Miyazawa T, Gallagher M, Preti G, Wise PM (2009c) Psychometric functions for ternary odor mixtures and their unmixed components. Chem Senses 34:753-761
Mori K, Mataga N, Imamura K (1992) Differential specificities of single mitral cells in rabbit olfactory-bulb for a homologous series of fatty-acid odor molecules. J Neurophysiol 67:786-789

Nagata Y (2003) Measurement of odor threshold by triangle odor bag method. In: Odor measurement review. Office of Odor, Noise and Vibration. Environmental Management Bureau, Ministry of Environment, Tokyo, pp 118-127

Natsch A, Derrer S, Flachsmann F, Schmid J (2006) A broad diversity of volatile carboxylic acids, released by a bacterial aminoacylase from axilla secretions, as candidate molecules for the determination of human-body odor type. Chem Biodivers 3:1-20

Punter PH (1983) Measurement of human olfactory thresholds for several groups of structurally related compounds. Chem Senses 7:215-235

Rabin MD, Cain WS (1986) Determinants of measured olfactory sensitivity. Percept Psychophys 39:281-286

Ranau R, Steinhart H (2005) Identification and evaluation of volatile odor-active pollutants from different odor emission sources in the food industry. Eur Food Res Technol 220:226-231

Rennaker RL, Chen CF, Ruyle AM, Sloan AM, Wilson DA (2007) Spatial and temporal distribution of odorant-evoked activity in the piriform cortex. J Neurosci 27:1534-1542

Repicky SE, Luetje CW (2009) Molecular receptive range variation among mouse odorant receptors for aliphatic carboxylic acids. J Neurochem 109:193-202

Saito H, Kubota M, Roberts RW, Chi Q, Matsunami H (2004) RTP family members induce functional expression of mammalian odorant receptors. Cell 119:679-691

Saito H, Chi Q, Zhuang H, Matsunami H, Mainland JD (2009) Odor coding by a mammalian receptor repertoire. Sci Signal 2:ra9

Schmidt R, Cain WS (2010) Making scents: dynamic olfactometry for threshold measurement. Chem Senses 35:109-120

Singer AG, Beauchamp GK, Yamazaki K (1997) Volatile signals of the major histocompatibility complex in male mouse urine. Proc Natl Acad Sci USA 94:2210-2214

Smallegange RC, Qiu YT, Bukovinszkine-Kiss G, Van Loon JJA, Takken W (2009) The effect of aliphatic carboxylic acids on olfaction-based host-seeking of the malaria mosquito anopheles gambiae sensu stricto. J Chem Ecol 35:933-943

Stettler DD, Axel R (2009) Representations of odor in the piriform cortex. Neuron 63:854-864

Stevens JC, Cain WS, Burke RJ (1988) Variability of olfactory thresholds. Chem Senses 13:643-653

van Gemert LJ (2003) Odour thresholds. Compilations of odour threshold values in air, water and other media. Oliemans, Punter \& Partners BV, Utrecht

van Thriel C, Schaper M, Kiesswetter E, Kleinbeck S, Juran S, Blaszkewicz M, Fricke HH, Altmann L, Berresheim H, Bruning $\mathrm{T}$ (2006) From chemosensory thresholds to whole body exposures-experimental approaches evaluating chemosensory effects of chemicals. Int Arch Occup Environ Health 79:308-321

Walker JC, Hall SB, Walker DB, Kendal-Reed MS, Hood AF, Niu XF (2003) Human odor detectability: new methodology used to determine threshold and variation. Chem Senses 28:817-826

Wise PM, Miyazawa T, Gallagher M, Preti G (2007) Human odor detection of homologous carboxylic acids and their binary mixtures. Chem Senses 32:475-482

Wisthaler A, Tamas G, Wyon DP, Strom-Tejsen P, Space D, Beauchamp J, Hansel A, Mark TD, Weschler CJ (2005) Products of ozone-initiated chemistry in a simulated aircraft environment. Environ Sci Technol 39:4823-4832

Yoshida M (1984) Correlation analysis of detection threshold data for 'standard test' odors. Bull Fac Sci Eng Chuo Univ 27:343-353 